\title{
Quantifying global sea level during warm periods
}

\section{P A L S E A}

\author{
Gaylen Sinclair'1 B.S. Lecavalier ${ }^{2}$ and K.L. Vyverberg ${ }^{3}$ \\ PALSEA2 Workshop, Tokyo, Japan, 22-24 July 2015
}

In July, the third meeting of the second PALeo constraints on SEa level rise (PALSEA2) working group convened at the University of Tokyo, with the goal of integrating data and model-based reconstructions of paleo climate, cryosphere, and sea level. Presentations focused on past warm periods (mainly the late Pliocene, the last interglaciation (LIG), and the Holocene) and periods of rapid change during the last glacial cycle.

Due to the fragmentary record of the Miocene and Pliocene, and chronological uncertainties with existing records, delegates agreed that obtaining accurate sea-level rates for this period is impossible; efforts should focus on better constraining the maximum amplitude (Fig. 1). Sea-level changes due to dynamic topography must also be considered at these timescales to accurately estimate global ice volume from the sea-level reconstructions; current model results show that the contribution from this process can be tens of meters and may account for the spatial variations in Pliocene sea-level fluctuations (Rovere et al. 2015).

For the LIG, model-corrected relative sealevel records indicate peak global mean sea levels of around six to nine meters (Fig. 1), although the timing and number of highstands differs between reconstructions.
In several areas, including the Seychelles, detailed study of fossil coral facies and lithology reveal sub-orbital sea-level fluctuations consistent with previous inferences from the Bahamas and the Red Sea (Thompson et al. 2011; Rohling et al. 2008). A single, global-mean sea-level reconstruction should enable eventual reconciliation of these disparate sea-level estimates, accounting for different sources of sea-level rise, including potentially different timings of retreat of the major ice sheets.

The Holocene sea-level history is relatively well constrained, although there is room for improvement in delimiting the spatial and temporal variability of sea levels. A primary source of uncertainty is the contribution from the Antarctic Ice Sheets due to the relative paucity of observational control and the difficulty in obtaining accurate dates from cosmogenic methods. For the past 2,000 years, application of a Gaussian process model supports the existence of sub-millennial changes in global mean sea level (Cahill et al. 2015); but the processes responsible for those changes remain a target for future research.

Several techniques for improving climatic forcings in models were also debated, highlighting differences between modeled
Present day
temperature $=\sim 0.9^{\circ} \mathrm{C}$
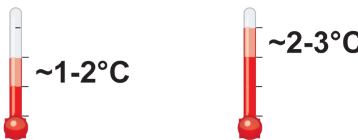

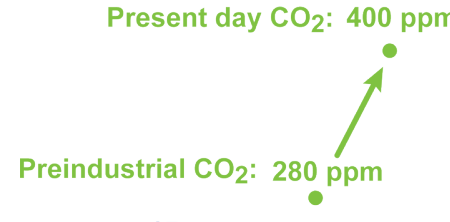

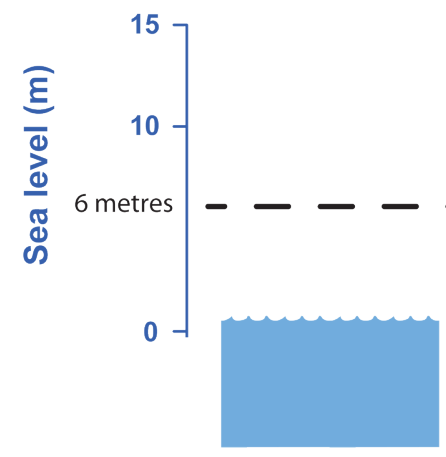

Present

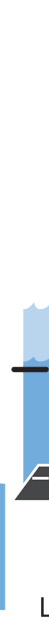$$
\text { 年 }
$$

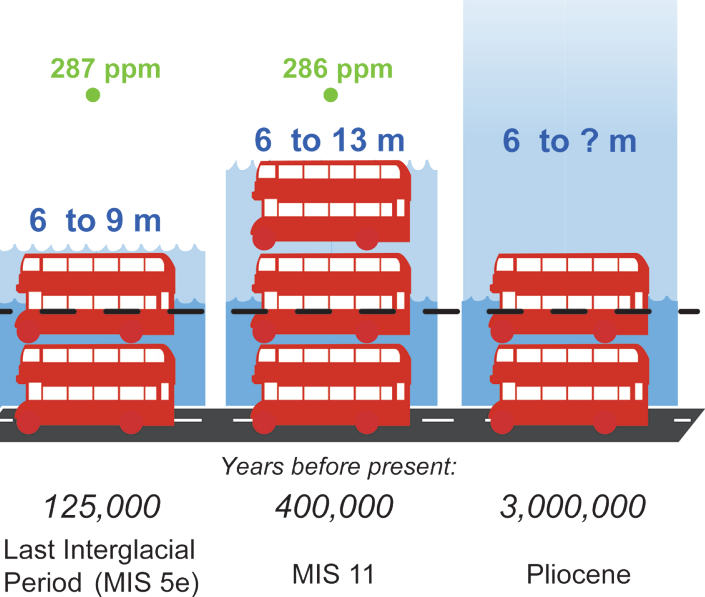

Figure 1: Summary figure of global mean sea level during past warm periods, global mean temperature relative to $1890 \mathrm{CE}$, and atmospheric $\mathrm{CO}_{2}$ levels. Adapted from Dutton et al. (2015)
LIG climates and compilations of ocean-temperature data. Coupling of ice-sheet and climate models is increasingly feasible, and critical for understanding reconstructed sea-level histories. The importance of developing transient simulations of past warm periods was stressed as a means to improve understanding of the spatial and temporal variability observed in ice-sheet and sealevel reconstructions.

While new paleoclimate data at present are often archived online, they are rarely compiled into intuitive databases that can be easily accessed by all end users, particularly the modeling community. Significant progress has been made since the last PALSEA2 meeting in developing a framework for new databases for use by paleoclimate and paleo sea-level communities (Düsterhus et al. 2015). Discussions continued at this meeting, where delegates stressed the importance of including all metadata for a given data point to facilitate standardization of data and accommodation of future interpretations and calculations. Discussions during the conference to clarify the uncertainties of various data and model outputs highlighted the importance of being more rigorous about reporting and explaining uncertainties. Such transparency will facilitate the interpretation and application of climate, cryosphere, and sea-level reconstructions, and will be critical to advancing data-model comparisons, as well as interdisciplinary collaborations.

\section{ACKNOWLEDGEMENTS}

Funding was provided from PAGES, INQUA, and the Atmosphere and Ocean Research Institute (AORI) at the University of Tokyo. We thank all the delegates and the local hosts - Yusuke Yokoyama, Ayako Abe-Ouchi and their research groups - for making the workshop a success.

\section{AFFILIATIONS}

${ }^{1}$ College of Earth, Ocean, and Atmospheric Sciences, Oregon State University, Corvallis, USA ${ }^{2}$ Department of Physics and Physical Oceanography, Memorial University of Newfoundland, Canada ${ }^{3}$ Department of Geological Sciences, University of Florida, Gainesville, USA

\section{CONTACT}

Gaylen Sinclair: gsinclair@coas.oregonstate.edu

\section{REFERENCES}

Cahill N et al. (2015) Ann Appl Stat 9: 547-571

Düsterhus A et al. (2015) Clim Past Discuss 11: 2389-2404

Dutton A et al. (2015) Science 349: 153

Rohling EJ et al. (2008) Nature Geosci 1: 38-42

Rovere A et al. (2015) Earth Sci Rev 145: 117-131

Thompson WG et al. (2011) Nature Geosci 4: 684-687 